\title{
BOM FIM: EXPOSIÇÃO DOS RECURSOS NATURAIS E CULTURAIS \\ DO DISTRITO BONFIM DE FEIRA - FEIRA DE SANTANA - BAHIA - \\ BRASIL
}

\section{GOOD ENDING: NA EXPOSITION OF THE NATURAL AND CULTURAL REOURCES OF THE BONFIM DE FEIRA DISTRICT -} FEIRA DE SANTANA - BAHIA - BRAZIL

\author{
Liana Maria Barbosa ${ }^{1}$ \\ Alisandra Souza Silva ${ }^{2}$ \\ Gracinete Bastos de Souza ${ }^{3}$ \\ Davi Cerqueira Grilo ${ }^{4}$ \\ Laina Freitas Melo ${ }^{5}$
}

O objetivo deste trabalho é relatar nossa experiência com a extensão, que resultou de pesquisa sobre o meio físico no distrito Bonfim de Feira. A área deste distrito é caracterizada pela presença de serras e maciços residuais esculpidos em rochas pré-cambrianas. Os bens culturais resultam de uma história de povoação provavelmente do final do século XVIII, com culturas religiosas (católica e afrobrasileira), tropeiros e boiadeiros, que dinamizaram o espaço, favorecendo a concentração populacional e as manifestações culturais.

Palavras-chave: extensão, geografia, história, memória, cultura.

The purpose of this work is present our experience with extension activities, that resulted from physical environmental research in the district of Bonfim de Feira. This area is characterized by mounts and residuals outcrops sculpted in precambrian rocks. The cultural resources were associated with the people occupation history probably in the final of XVIII century under the catolic and afro-brazilian religious influences, troops and cowboys tracks which promote the urban development, the origin of this village and the cultural manifestations.

Key-words: extension, geography, history, memory, culture.

\footnotetext{
1 Graduada em Geologia (UFCE), Mestre e Doutora em Geologia (UFBA). Docente titular da Universidade Estadual de Feira de Santana. liana@uefs.br

${ }^{2}$ Graduada (bacharel) em Geografia (UFG) e Licenciada na mesma área (UEFS). Atuou na Iniciação Científica (bolsista FAPESB).

${ }^{3}$ Graduada em Engenharia Civil (UEFS), Mestre em Geotecnia (UnB) e Doutora em Geotecnia (USP). Docente da Universidade Estadual de Feira de Santana. gracinet@uefs.br

Graduação (bacharelado e licenciatura) em Geografia (bolsista Probic/UEFS) e Mestre em Modelagem em Ciências da Terra e do Ambiente (UEFS).

${ }^{5}$ Graduação em Geografia (UEFS), foi bolsista PIBIC/CNPq/UEFS.
} 


\section{INTRODUÇÃO}

O projeto "Bonfim de Feira em foco: exposição dos recursos naturais e materiais de construção para a comunidade" é uma extensão natural do projeto de pesquisa "Recursos Naturais e Materiais de Construção em Feira de Santana" desenvolvido no distrito Bonfim de Feira. Este distrito localiza-se no setor oeste do município de Feira de Santana e tem aproximadamente $34 \mathrm{~km}^{2}$ (Fig. 1). Com uma população estimada em 3.788 habitantes (IBGE, 2000), este contingente representa $0,79 \%$ do total populacional do município. Apresenta características rurais e urbanas, com uma economia local dependente da pecuária, da cultura de fumo, da cultura de subsistência (feijão e milho) e de modesto comércio. Possui três escolas públicas na sede distrital e oito nucleadas na zona rural, que atendem pelo menos 1.000 crianças e adolescentes. 


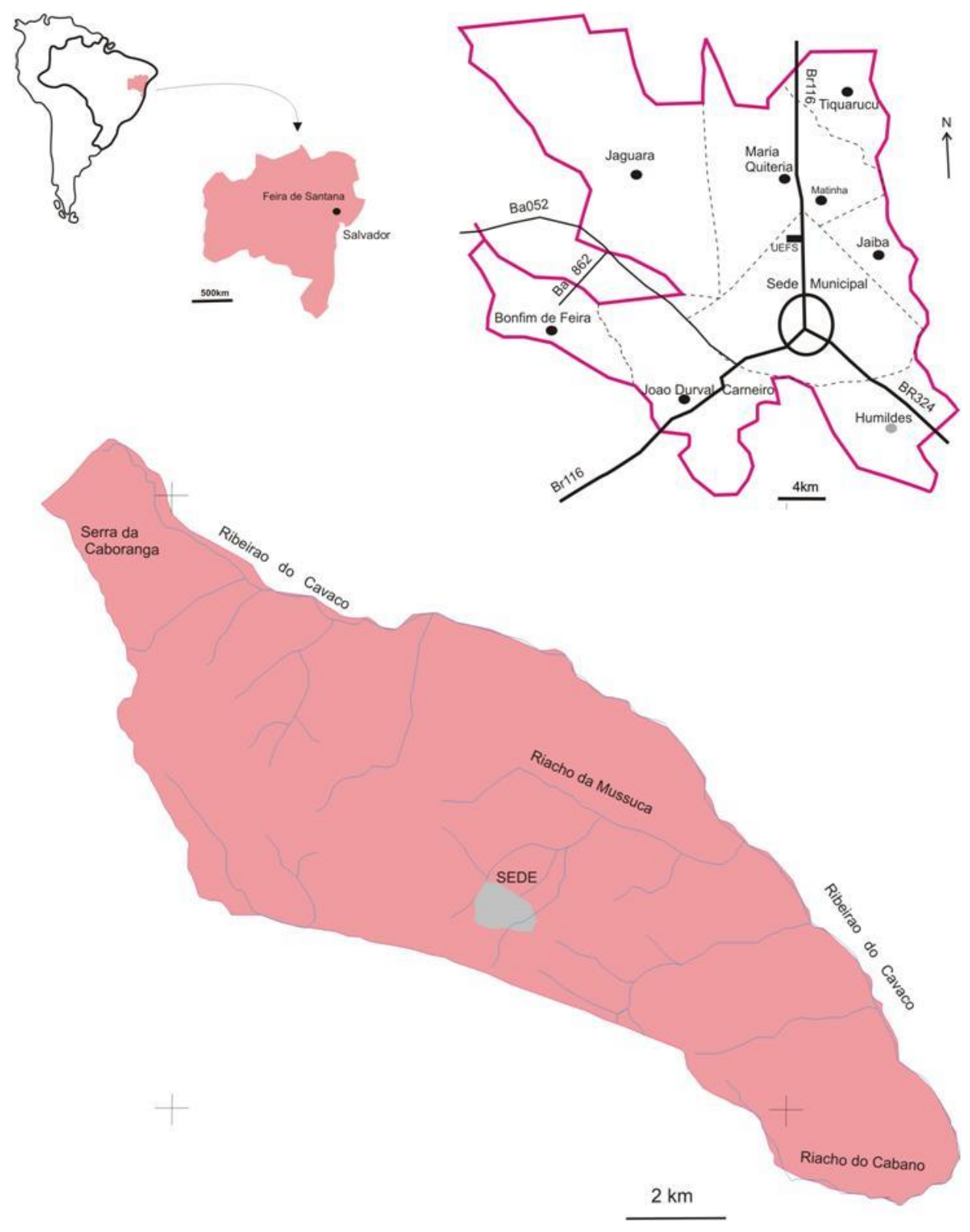

Figura 1 - Localização do distrito de Bonfim de Feira (Silva 2007, 2008)

No período de março/2006 a dezembro/2008, a equipe desenvolveu pesquisa no distrito Bonfim de Feira, contribuindo com a formação em iniciação científica de três estudantes do curso de Geografia: Davi Cerqueira Grilo, bolsista PROBIC-UEFS (2006 - 2007); Alisandra de Souza Silva, bolsista FAPESB (2006 - 2008) e Laina de Freitas Melo, bolsista PIBIC-CNPq (2008 - 2010). No primeiro ano do projeto, um painel informativo (os objetivos e os métodos da pesquisa) foi fixado na biblioteca pública local em outubro de 2006. Foi uma iniciativa importante, que abriu canais de 
aproximação entre a equipe e a comunidade, inclusive com a integração de Glorelice Almeida Santana, funcionária da biblioteca local, como apoio ao projeto (Fig. 2).

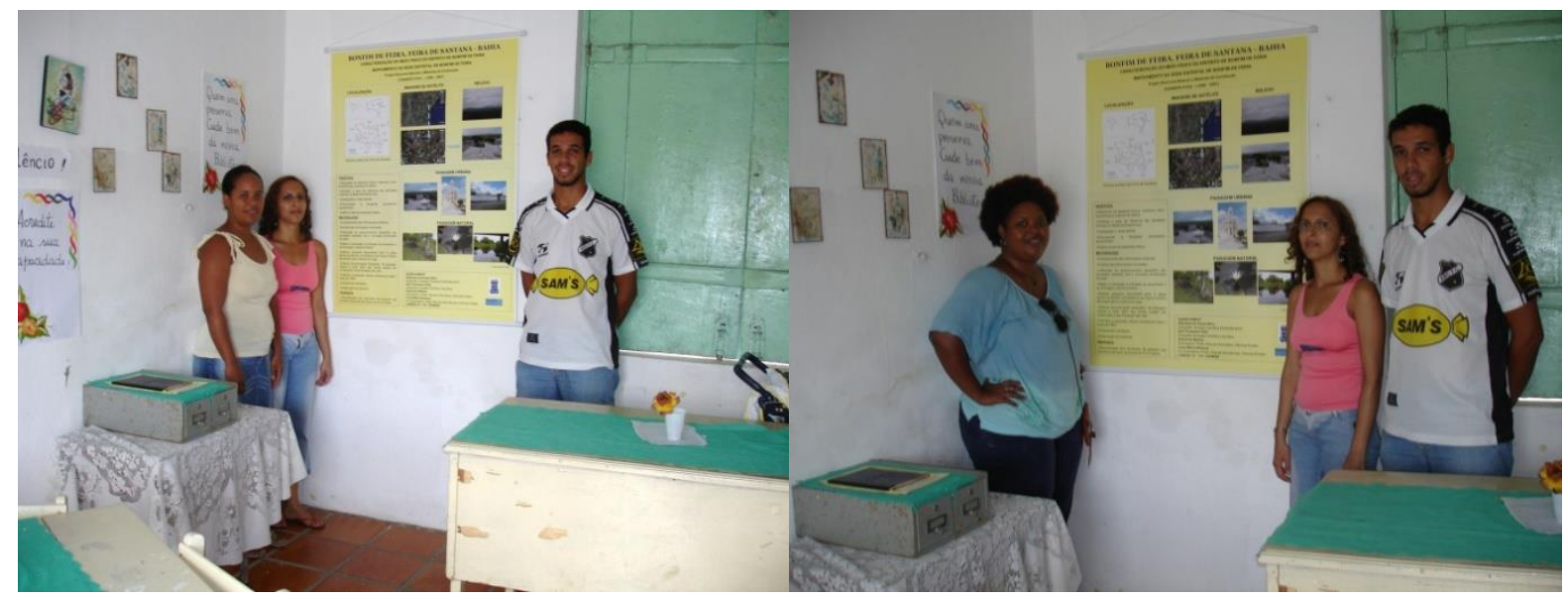

Figura 2 - Fixação do painel informativo sobre a pesquisa na Biblioteca Pública Godofredo Leite. Da esquerda para a direita: Glorelice Almeida, Alisandra Silva, Davi Grilo e Gracinete Souza (Acervo do projeto: outubro/2006)

A aproximação entre pesquisadores e população definiu outros rumos para a investigação e orientaram a elaboração do projeto de extensão "Bonfim de Feira em foco: exposição dos recursos naturais e materiais de construção para a comunidade", com quatro fases de execução: $\left(1^{a}\right)$ organização, aquisição de infraestrutura e elaboração de documentos, dentre os quais o vídeo-documentário "BOM FIM: Bonfim em foco" com uso de aplicativo "windows movie maker"; $\left(2^{a}\right)$ realização

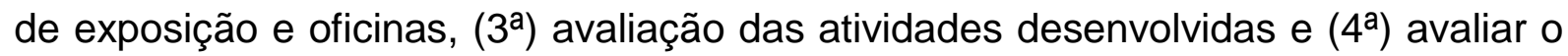
projeto, elaborar relatórios, socializar os resultados com a fixação permanente dos painéis demonstrativos nas escolas e biblioteca locais e divulgação a experiência em eventos científicos.

Portanto, o objetivo deste trabalho é relatar o que realizamos no período de 09 a 12 de julho de 2009, que caracterizamos como Parte I, início da segunda fase. Trata-se de uma exposição para a comunidade, que ocorreu no Salão Paroquial e na Escola Municipal Álvaro Pereira Boaventura (Fig. 3) com a seguinte programação:

(a) painéis/murais - "O meio físico e o diagnóstico geoambiental do distrito", resultado direto da pesquisa de Alisandra de Souza Silva (SILVA, 2007, 2008); "a linha de tempo do distrito", que foi construída com base em relatos e documentos (fotografias, recibos etc.) fornecidos pela própria população e outros documentos, tais como documentos cíveis e jornais antigos de Feira de Santana; "as vozes da 
memória", que se refere às fotografias da população informante e de personalidades locais.

(b) 20 amostras de principais minerais formadores de rocha, minérios, rochas do substrato local e rochas, que são utilizadas na pavimentação de ruas e calçadas da sede distrital.

(c) 10 placas de amostras de solo exibindo cores diferentes, incluindo os solos locais.

(d) duas placas de grãos de minerais pesados, que foram observados com uso de lupa binocular.

(e) pares de fotografias aéreas, visualizados com uso de aparelho estereoscópico de espelho, além de mapas do distrito (drenagem, relevo, geologia simplificada) de autoria de Silva $(2007,2008)$.

(f) vídeo documentário - BOM FIM: Bonfim em foco produzido pela equipe com base nos resultados obtidos durante a pesquisa.

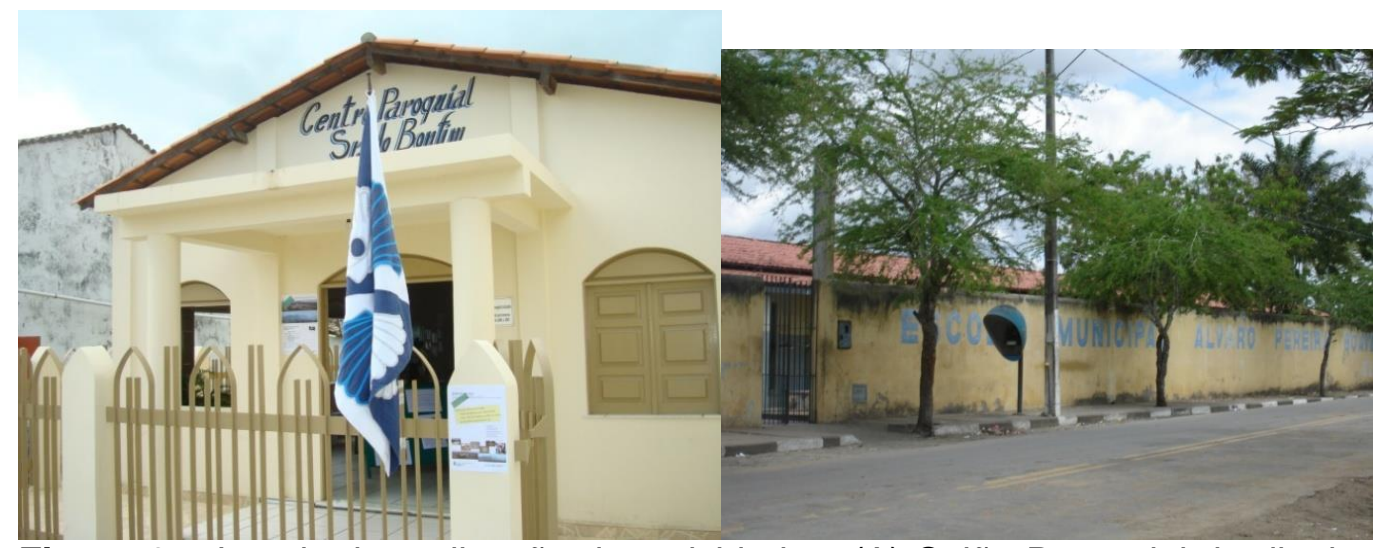

Figura 3 - Locais de realização das atividades: (A) Salão Paroquial do distrito e (B) Escola Municipal Álvaro Pereira Boaventura

A apresentação do vídeo foi prevista para apenas uma exibição na escola municipal. Entretanto, foram feitas seis exibições adicionais: uma na escola e as demais no Salão Paroquial (Figs. 3 e 4). No salão paroquial, a presença freqüente de crianças entre 3 e 12 anos provocou a equipe na improvisação de uma bancada com lápis de cores e papel para realização de pinturas. 


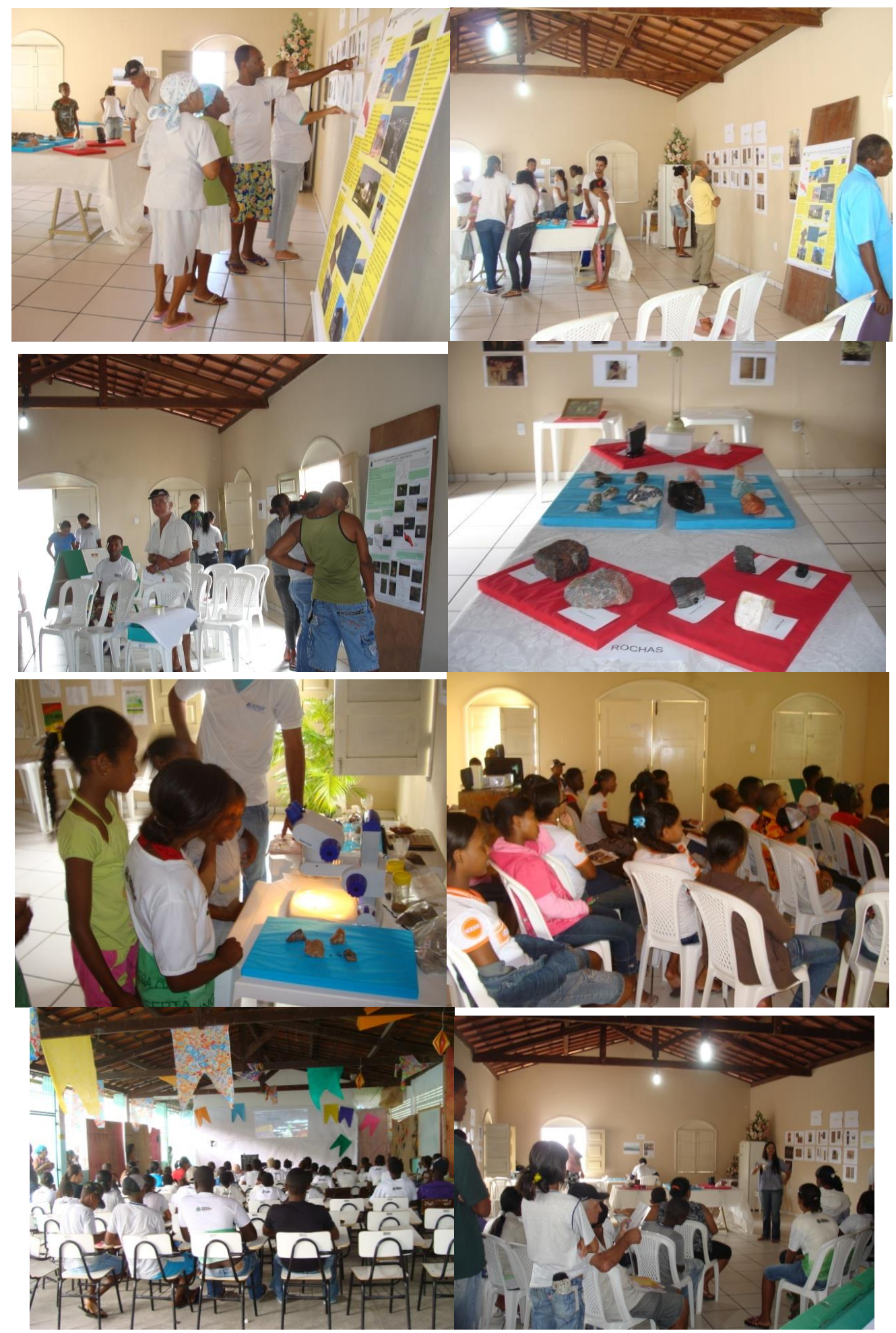

Figura 4 - Imagens das atividades no período de 09 a 12 de julho de 2009

\section{MOTIVAÇÃO E ESCOLHA DO LUGAR}

O objetivo inicial da pesquisa referia-se à caracterização do meio físico, dos materiais de construção e dos aspectos ambientais, sócio-econômicos e culturais do 
distrito. Estes últimos poderiam ser descritos com base em dados secundários disponibilizados pelo Instituto Brasileiro de Geografia e Estatística - IBGE.

A escolha do local de estudo se fundamentou no baixo índice de vulnerabilidade ambiental, que Barbosa (2004) determinou para Bonfim de Feira. Este índice indica alta resiliência do meio físico em recuperar a paisagem natural.

Portanto, somando este índice aos outros parâmetros, tais como pequena extensão areal e baixa densidade demográfica, a equipe concluiu que o projeto seria factível e de baixo custo. Os dados do meio físico e os relatos da população mostraram que o índice de vulnerabilidade de Barbosa (2004) precisa ser refeito e que o lugar registra informações e manifestações culturais relevantes para compreensão da história de Feira de Santana. Estas conclusões e os relatos da população motivaram a elaboração e o desenvolvimento do projeto de extensão: "Bonfim de Feira em foco: exposição dos recursos naturais, culturais e materiais de construção para a comunidade". Este projeto foi aprovado pelo Conselho Superior da UEFS (CONSEPE 68/2008) e recebeu selo do AIPT - Ano Internacional do Planeta Terra na lista de projetos do ano de 2009 (http://aipt.mct.gov.br/index.php/ content/view/114.html).

As visitas à área de estudo aproximou pesquisadores e população. Os próprios habitantes foram indicando outros populares como auxílio ao mapeamento do meio físico na zona rural e na sede, bem como à descrição da história, da cultura, da memória do Bonfim. A equipe ouviu relatos informais e espontâneos da história, da cultura, da economia e do cotidiano do lugar. Ao fim, foram trinta e cinco pessoas, que passamos a designar de "Vozes da Memória", importantes para a compreensão do povoamento do distrito.

Como conseqüência, elaboramos o vídeo-documentário, que foi exibido previamente para a população em 05 de abril de 2009. Esta exibição teve duas razões. A primeira delas o interesse em revelar para a população, que os relatos orais apresentados pela mesma foram significativos para construção da narrativa histórica e cultural do Bonfim, e, para registro da memória do lugar. A segunda corresponde ao caminho para solicitação de consentimento desta população para uso das imagens e relatos. 


\section{MEIO FÍSICO E DIAGNÓSTICO GEOAMBIENTAL}

O mapeamento do meio físico e o diagnóstico geoambiental resultaram na construção de mapas georeferenciados dos aspectos geológicos, do relevo, da rede de drenagem e dos problemas ambientais, tanto na sede distrital quanto na área rural. O substrato rochoso é caracterizado pela presença de rochas cristalinas précambrianas metamorfizadas e bastante fraturadas. A rede de drenagem é marcada por riachos intermitentes, com a principal drenagem traçada pelo Ribeirão do Cavaco, que recebe águas do Riacho da Mussuca e do Cabano. O escoamento se dá preferencialmente na orientação NO-SE. Os terrenos mais baixos estão situados nas proximidades do Ribeirão do Cavaco (aprox. $180 \mathrm{~m}$ de altitude) e os mais elevados na Serra da Caboranga (540m de altitude). O relevo é caracterizado pela presença de serras e maciços residuais, com destaque para as Serras da Caboranga e a da Mata. Os problemas ambientais mais comuns estão associados com o desmatamento, erosão por escoamento superficial, erosão pela abertura de "cascalheiras" (áreas informais para extração de brita), assoreamento dos riachos, lixo e esgotamento a céu aberto. Estes dois últimos itens, comuns na sede distrital. Estes problemas produzem conseqüências danosas ao meio físico e à saúde da população (Silva 2008, 2009).

\section{A LINHA DE TEMPO DO DISTRITO}

A origem da povoação é provavelmente do final do século XVIII, a tirar pelo registro de doação do terreno da capela - 20 de agosto de 1783. Esta doação foi feita pelo casal Bernarda Maria da Conceição e Manoel Antonio de Bastos.

Em 1803, o local recebeu a outorga de Paróquia da Vila de Bomfim e seu primeiro pároco foi João Joaquim de Carvalho. Para tal definição, a província colonial da Bahia provavelmente dava importância a este lugar. Em 1835, a Vila do Bonfim somava 307 casas e uma população de 1406 pessoas, com a população afrodescendente estimada em 415 pessoas, dos quais 41 eram negros libertos. Neste tempo, provavelmente se inicia a construção da Igreja Matriz com duas torres, uma delas dedicada ao Senhor do Bonfim e a outra ao São João Nepomuceno.

O lugar recebeu a outorga de Freguesia do Senhor do Bomfim ou Senhor Bom Jesus do Bomfim em 16 de julho de 1859. O Cônego José Cupertino Lacerda chega ao Bonfim em 1881. Importante orador e de forte influência na política, 
administra esta freguesia até 1925, quando falece. Seus restos mortais foram depositados em jazigo no sopé do altar-mor da Igreja.

A arquitetura popular exibe várias construções em estilo eclético, ainda preservadas, que foram edificadas no início do século $X X$. O comércio que foi dinamizado pela passagem de boiadas e tropas. Os boiadeiros e os tropeiros eram atraídos pelos festejos tradicionais, a exemplo da festa em homenagem ao Senhor do Bonfim, que eram noticiados em toda a região; existia uma farmácia com atendimento médico e duas escolas públicas: uma para o sexo feminino e outra para o sexo masculino e também, era o tempo das filarmônicas locais: Minerva e Ceciliana (Fig. 5). Quanto às manifestações afro-brasileiras não ocorriam livremente, seus adeptos sofriam perseguições até meados do século XX. 

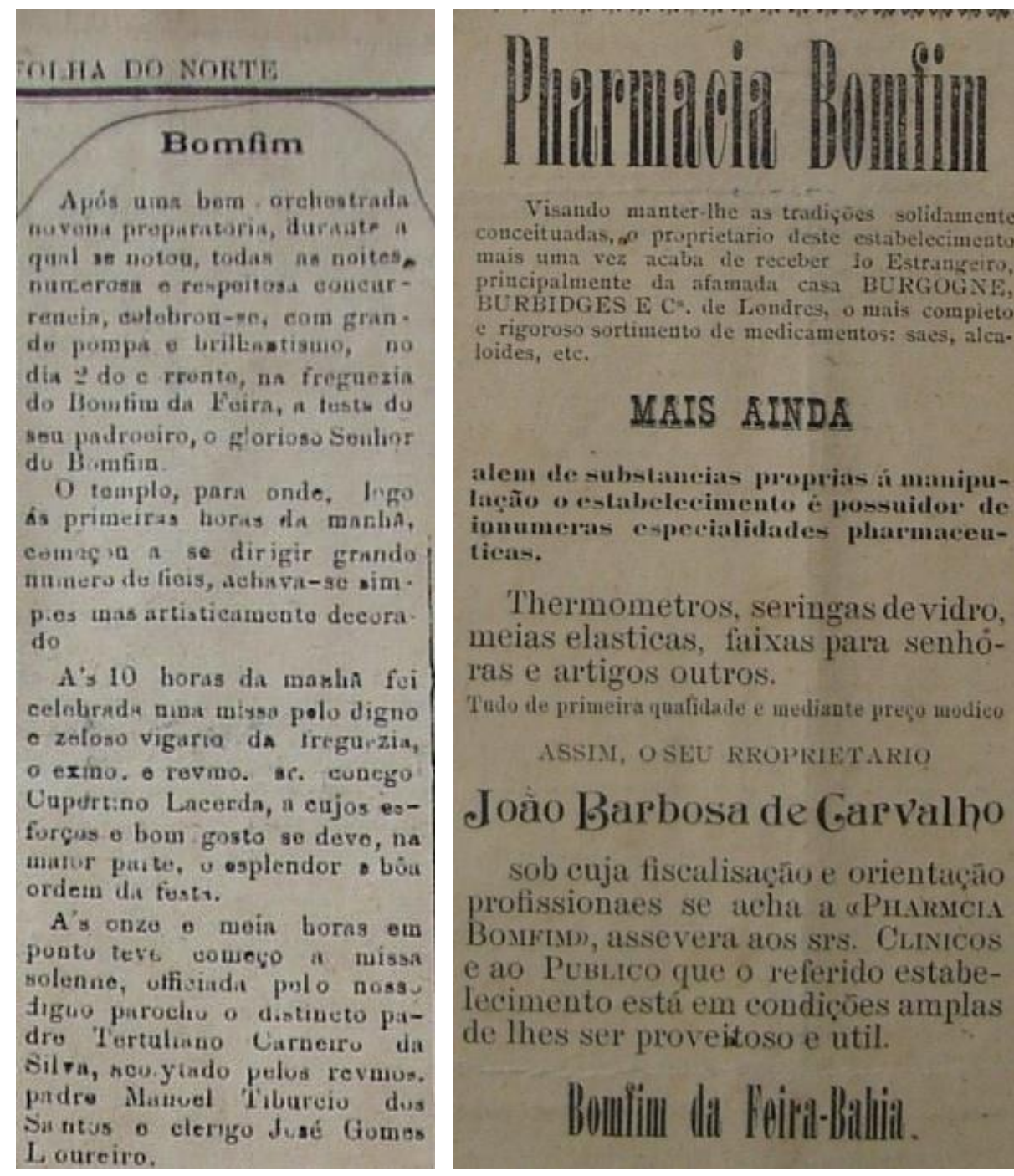

Visando manter-lhé as tradiçồ solidamente conceituadas, no proprietario deste estabelecimento mais uma vez acaba de receber fo Estrangeiro, principalmente da afamada casa BURGOGNE, BURBIDGES E C^. de Londres, o mais compieto e rigoroso sortimento de medicamentos: saes, alca. loides, etc.

\section{MAIS AINDA}

alem de substaucias moprias á manipuIação o cotabelecimento é possuidor de innumeras e-pecialidades pharmaceuticas.

Thermometros, seringas de vidro, meias elasticas, faixas para senhóras e artigos outros.

Tudo de primeira quafidade e medisnte prego modico

$$
\text { ASSIM, OSEU RROPRIETARIO }
$$

\section{Joào Barbosa de Garvalho}

sob cuja fiscalisaçấo e orientaçẩo profissionaes se acha a Рн.мkмci. Bomfind, assevera aos srs. Chinicos e ao Publico que o referido estabelecimento está em condiçôes amplas de lhes ser proveitoso e util.

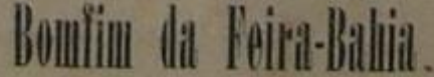

Figura 5 - Recortes de jornais, da esquerda para a direita: nota sobre a festa do Senhor do Bonfim, anúncio da "Pharmacia Bomfim" e nota sobre o processo eleitoral nas escolas locais (Folha do Norte, 1911) e recibo da filarmônica Ceciliana de 1923. 
Os tropeiros e os vaqueiros foram muito importantes na dinamização do lugar. Estas terras eram pontos de parada destes grupos, que realizavam a comunicação do lugar com o Recôncavo Baiano e eventualmente ao litoral, através da Estrada da Cachoeira. Foi assim, que no século XVIII, o povoado torna-se caminho do gado ou por conta do caminho do gado torna-se povoado. Foi local de pouso para boiadeiros, vindos "das bandas de Minas e Goiás". Da mesma maneira, vieram os tropeiros, elementos importantes na comunicação e povoamento do sertão nordestino. Contam moradores antigos, que a chegada das tropas era anunciada pelas sinetas da mula enfeitada e a criançada corria para vê-las entrar na vila. O comércio se estabeleceu e o lugar prosperou. Tanto para os tropeiros quanto para os boiadeiros, a Estrada da Cachoeira era a principal referência de comunicação do lugar até a década de 1930, quando foi aberta a Estrada da Feira, durante o governo de Getúlio Vargas.

O coreto foi construído para as tocatas das filarmônicas (1937). O cruzeiro de madeira foi substituído por alvenaria e coberto com brita escura - rochas ferromagnesianas (1939). A Igreja Matriz teve sua estética frontal completamente modificada, com uma torre central e estilo neoclássico. Estes monumentos compõem o principal e mais bem preservado conjunto de arquitetura civil e religiosa do local (Fig. 6).
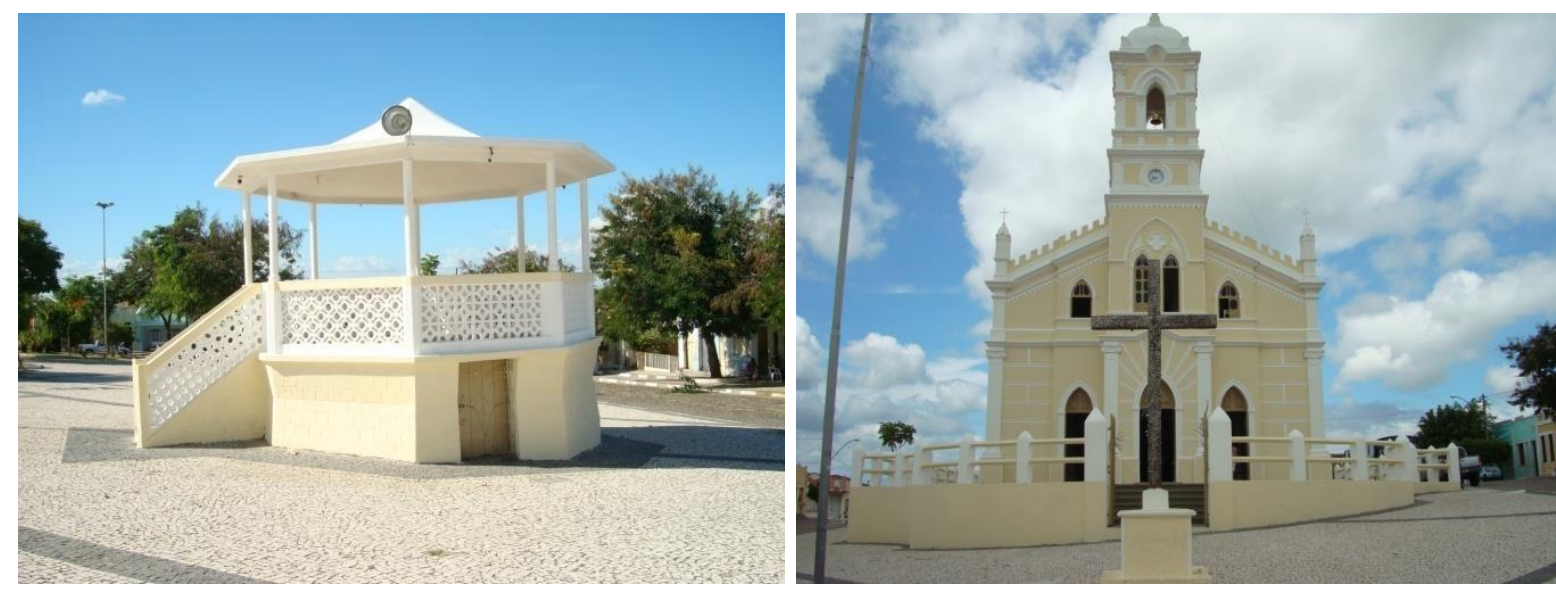

Figura 6 - Conjunto monumental da Praça da Matriz - Coreto, Cruz e Igreja (Fonte: Acervo do Projeto, fotografias de abril de 2009)

Estas modificações ambientais coincidiram com o período de mudança da toponímia brasileira determinada no governo de Getúlio Vargas. A toponímia brasileira sofreu alteração para designações de origem tupi-guarani (em tese). E assim, este lugar passou a chamar-se Itacuruçá, que significa pedra em cruz ou cruz 
de pedra. Contudo, esta denominação não vingou, e, em 1943, retoma-se a designação Bonfim de Feira, dito também Bonfim da Feira, que persiste até os dias atuais.

As boiadas cruzavam semanalmente estas terras, mas na década de 1940 em diante, o rumo das boiadas era o "Campo do Gado" (em Feira de Santana), não mais "tocados" por vaqueiros montados em cavalos, mas com uso de veículos motorizados.

Entre 1960 e 1964 (?), o cine Flor de Lis é mantido por Guilherme Bastos, Severiano Bastos, Jorge Smera e outros em um sobrado atrás da Igreja Matriz. Foi deste período, que a serra do Bonsucesso, que se situa no setor noroeste do distrito, serviu de cenário de "O grito da terra", filme do cineasta Olney São Paulo em parceria com o escritor Ciro Leite de Carvalho, filho deste distrito. Conta-se que este filme foi exibido no Flor de Lis (Fig. 7).

Vários filhos locais tornaram-se influentes na política de Feira de Santana, porém destacamos quatro personalidades, que são referenciadas pelas "vozes da memória". Destes, apenas um é mencionado em compêndios formais - o padre Cupertino Lacerda, que é reconhecido pelo poder instituído, seu nome encontra-se registrado em ruas e praças locais, em Feira de Santana e em Salvador. As demais personalidades são reconhecidas pela tradição oral e tiveram um papel importante na comunidade (Fig.8).

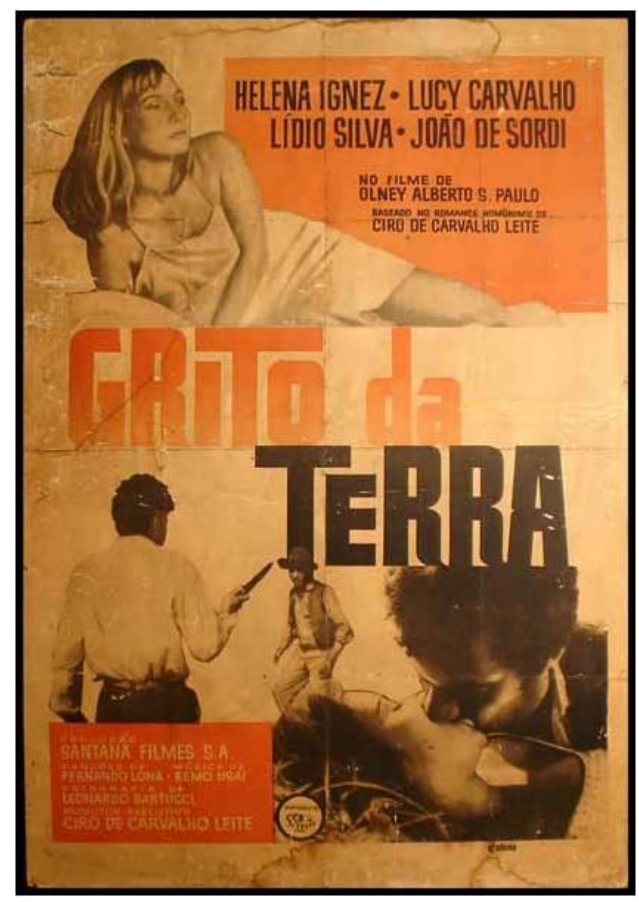

Figura 7 - Cartaz do filme do cineasta Olney São Paulo (1963/1964) 


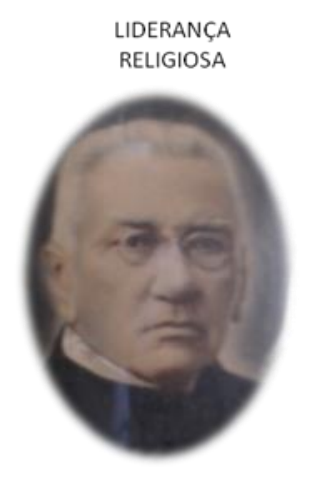

Padre Cupertino Lacerda $1850-1927$

\begin{tabular}{l} 
O Padre Cupertino, natural \\
de Santo Amaro, residiu \\
em Bonfim de Feira por 46 \\
anos. Exerceu influência \\
religiosa e política. Famoso \\
por seus sermões, após \\
sua morte, o "Sermão \\
Nossa Senhora e Santa \\
Isabel" de sua autoria, \\
entrou para a história da \\
literatura brasileira \\
\hline
\end{tabular}

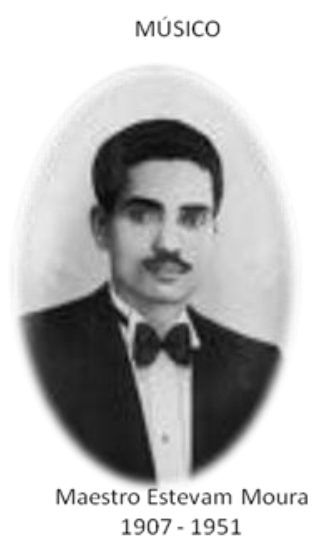

Natural de Santo Estevão, maestro, regeu a Minerva do Bomfim de 1925 a 1931. Foi regente de outras filarmônicas, como a 25 de Março da cidade da Feira de Santana. Suas composições marcam a história das filarmônicas baianas

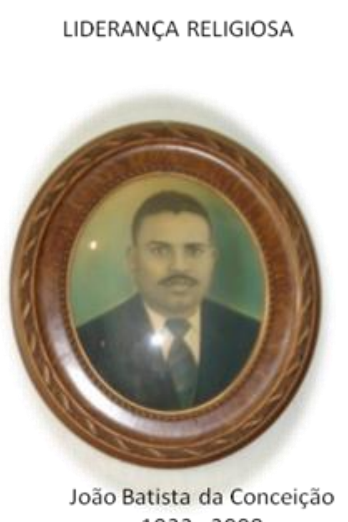

$1932-2008$

\begin{tabular}{l} 
João da Conceição nasceu \\
em Bonfim. Aos oito anos \\
foi iniciado na cultura afro- \\
brasileira. Tinha forte \\
ligação com o Igreja \\
Católica e o Santuário de \\
Santo Antonio. Babalorixá, \\
curador, líder espiritual, \\
ficou conhecido o velho \\
João do Jenipapo \\
\hline
\end{tabular}

FARMACẼUTICO PRÁTICO

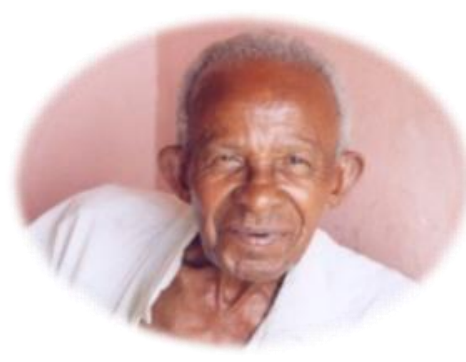

Raimundo Araújo dos Santos $1924-2008$

Raimundo, mais conhecido
como loiô, nasceu em
Bonfim. Foi farmacêutico
prático, um médico dos
pobres. Aprendeu com o
médico Theódulo Bastos
como usar ervas e produção
derremédios. ruas
indicações eram muito bem
vindas

Figura 8 - Personalidades registradas na história oral.

Em Bonfim de Feira, a música (filarmônicas, ternos), o cinema (sala de projeção, cenário), a feira livre e o antigo mercado compõem as manifestações culturais que representam memória, ou seja, elementos culturais que não mais são observados no costume local. Entretanto, as principais celebrações religiosas preservadas reúnem credo católico e afro-brasileiro, assegurando novenários, missas e procissões conforme se apresentam nos cultos católicos e aberturas dos terreiros com o rufar dos tambores como desígnios dos rituais afro-brasileiros. Há registros de seis terreiros na sede distrital e três na zona rural. Os lideres são zeladores de santos e são considerados curadores ou rezadeiras, quando mulheres. Ronaldo Sena (http://members.tripod.com/bmgil/rss11.htm, acesso em 27/02/2009) descreve o ritual liderado pelo Velho João do Jenipapo como candomblé católico, onde os santos são os guias dos orixás. Os rituais são, de uma maneira geral, denominados de samba e as celebrações unem santos católicos, orixás, caboclos, encantados, onde se misturam imagem cabocla e indígena. Os altares e os rituais são típicos de Umbanda, onde o sincretismo católico e africano é marcante. Os materiais minerais presentes nos altares são principalmente rochas de calcárias, 
quartzo e seixos rolados de diversos tipos de rocha.

Não somente crenças católica e afro-brasileira estão presentes na sede e na zona rural do Bonfim de Feira. O protestantismo também está presente com pelo menos cinco tendências. Centros espíritas de orientação kardecista não foram observados em Bonfim, pelo menos se existem não são bem visíveis como os demais credos. Porém, a história do espiritismo brasileiro registra o nome da professora e poetisa bonfinense, autora de "Ciranda da Vida" - Maria de Carvalho Leite (1900 - 1959), que adotou o pseudônimo de Dolores e bem presente na psicografia do mineiro Chico Xavier.

As cavalgadas, os festejos juninos e as vaquejadas são eventos fortes. $O$ futebol tem seu espaço, um campo cujo substrato rochoso aflora e não impede os campeonatos locais.
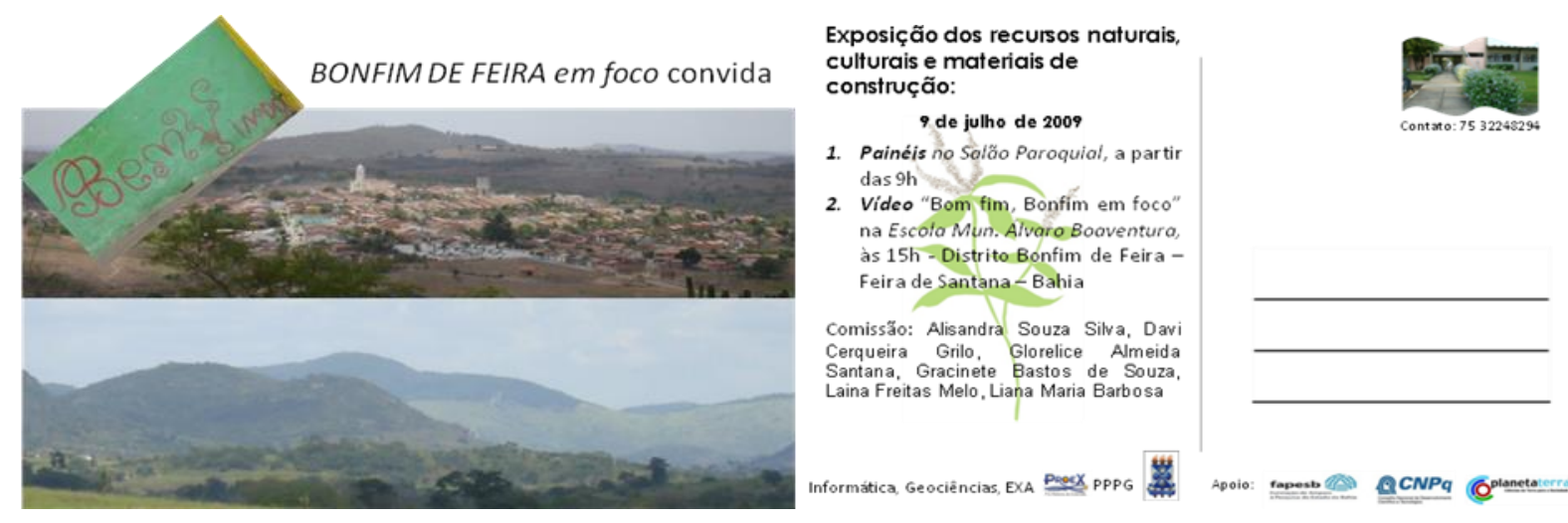

Figura 9 - Cartão convite exibindo fotografias das serras e da sede distrital, além da programação e comissão organizadora

\section{CONSIDERAÇÕES FINAIS}

O convite mostra um pouco do meio físico e do contorno urbano (Fig. 9). O vídeo-documentário revela "o meio físico e o diagnóstico geoambiental do distrito Bonfim de Feira" por Alisandra de Souza Silva, "o mapeamento da sede distrital" por Davi Cerqueira Grilo, "a geografia e a história", "as crenças" (católica, afro-brasileira, evangélica) e "as vozes da memória" pela equipe e população do Bonfim. Os recortes da memória expressam a tristeza pelas modificações ambientais com o desmatamento, a origem do nome, o amor pelo lugar, a escolha deste lugar como local de moradia, os vaqueiros e as boiadas, as filarmônicas, os ternos, o samba de 
roda e de coco, as festas tradicionais, as rezadeiras e curadores, o futebol, a capoeira, o clube e a farmácia (manipulação de remédios), que foram descritos e lembrados pela população "se aqui é o Bonfim, foi porque o Senhor do Bonfim apareceu aqui” (d. L). "eu fiquei tão triste, quando vi, que tiraram toda a mata ..." (d.F), "aqui passava boiada toda semana" "as vaquejadas de hoje são um esporte, um lazer, antigamente não, antigamente era para pegar boi no mato" (Sr. Z), "Mas você nem era nascido, como é que você sabe?" (Sr. C). "Eu ouvi, os caras olhando, falando ... (Sr. T)”. Ao final do lançamento de exibição deste vídeo, Sr. AV pediu o microfone e nos presenteou com aboio e repente. Ao ouvir os relatos do Sr. Z, parecíamos acompanhar "Estas Estórias" de Guimarães Rosas, com o Sr. AV, presenciamos um momento de "Estas Estórias" por um vaqueiro do Bonfim.

$\mathrm{Na}$ exposição, ocorreram questionamentos sobre o projeto, nossos objetivos, o que esperávamos encontrar no distrito, o que propomos para os problemas locais. A linha de tempo do distrito e o mural fotográfico foram bastante comentados pelos adolescentes e pelos adultos. O uso da lupa binocular (para visualização de grãos minerais) e a mesa de pintura foram os principais atrativos para as crianças.

Nas pinturas, as crianças reproduziram palavras presentes no vídeo, a exemplo de "bem vindos", "geografia do Bonfim", "assembléia de deus", "mensagens para as professoras", bem como desenhos das montanhas e da praça principal do lugar (Fig. 10). Algumas crianças permaneceram até a saída do grupo. No final, ouvimos que cantarolavam "Ogodô, ano 2000" e "Feira de Santana" duas músicas de autoria de Tom Zé, que foram utilizadas na trilha do vídeo.

Portanto, isto tudo é motivação para a continuidade e cumprimento das demais etapas do projeto, e, certamente com mais afinco e prazer. Inspirados nestas crianças, um quebra-cabeças $(1,5 \mathrm{~m} \times 1,0 \mathrm{~m})$ do traçado urbano da sede foi elaborado para aplicação na Parte II. Pensamos na brincadeira, no exercício de cartografia e no mapeamento da sede distrital que será exibido nesta próxima etapa.

Nossa pesquisa reúne indícios e registros que a história rural e urbana de Bonfim sofreu intervenção da cultura católica, da cultura afro-brasileira, dos tropeiros e dos criadores de gado. A estadia de tropeiros e vaqueiros no local dinamizou o espaço, movimentando o comércio e as manifestações culturais, que ainda permanecem no costume local, tais como festejos religiosos, vaquejada e cavalgada. Ocorreram transformações, é certo. Houve momento em que o lugar foi mais prospero. As construções e parte dos costumes revelam transformações sociais, a 
tradição e o moderno. A "filarmônica", o "padroeiro esquecido", a "toponímia singular", o "sincretismo de religiões", a "arquitetura" e as "lendas", nada mais são do que memória, contramemória, fato e lenda, que inflama a curiosidade para buscar e investigar o que há mais.
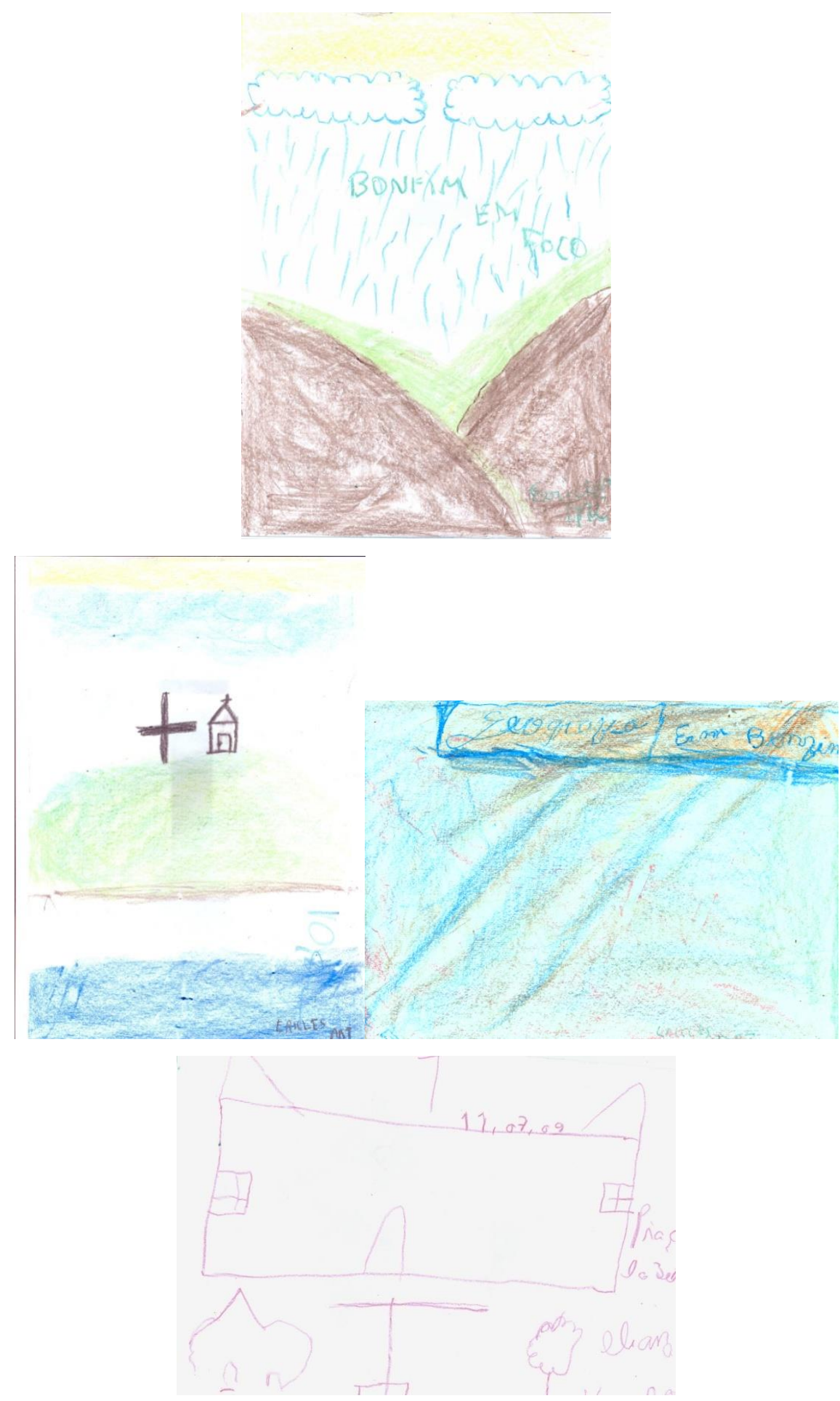

Figura 10 - Exemplos de desenhos, que apresentam as montanhas, a praça com a Igreja e o Cruzeiro e a Geografia em Bonfim 
Para tal, com linha de atuação com o meio físico, os autores buscam inspiração em Abreu (1960), Bosi (2001), Boaventura (2006), Cascudo (2001), dentre outros.

O Salão Paroquial (Praça Padre Lacerda) e a Escola Municipal Álvaro Boaventura (Rua da Feira) foram os palcos iniciais da exibição dos resultados da pesquisa. Porém, outras exposições estão programadas e os painéis produzidos serão entregues nas instituições públicas: escolas e biblioteca do distrito Bonfim de Feira. Em agosto/2009, prevemos a exibição do "mapeamento da sede distrital, a arquitetura, as pedras da rua e os materiais construtivos". Em outubro/2009, no decorrer da VI Semana Nacional de Ciência e Tecnologia, prevemos a reunião do que foi produzido e exibido nas exposições anteriores, acrescentando a apresentação das manifestações culturais.

\section{Agradecimentos}

Somos gratos à comunidade do Bonfim de Feira, que teve um papel fundamental no desenrolar de nosso projeto (pesquisa e extensão) e aos motoristas da UEFS, que nos conduziram àquela região; ao apoio da Pró-reitoria de Extensão da UEFS e do Departamento de Ciências Exatas; aos amigos Acácia, Agda, Haroldo, Maíse, Malena, Marilda, Zé Carlos e Victor.

\section{REFERENCIAS}

ABREU, JC. Caminhos antigos e povoamento do Brasil. Rio de Janeiro: Briguiet, 1960.

BARBOSA, LM. (org.) Recursos naturais e um painel didático: rochas, minerais, fosseis, solos, sedimentos e solos. Relatório de pesquisa (1998 - 2000). Feira de Santana: UEFS, 2000.

BARBOSA, LM. (coord.) Recursos naturais (minerais) e materiais de construção. Relatório de Pesquisa (2001 - 2004). Feira de Santana: UEFS. 2004.

BOAVENTURA, E.A. A paisagem urbana e o homem: memórias de Feira de Santana. Feira de Santana: UEFS, 2006. 
BOSI, E. Memória e sociedade: lembranças de velhos. São Paulo: Companhia das Letras, 2001.

BUENO, F.S. Grande dicionário etimológico-prosódico da lingua portuguesa: vocabularios da lingua portuguesa e cientifica - sinônimos contribuições do TupiGuarani. São Paulo: Saraiva, 1968.

CASCUDO, LC. Superstições do Brasil. São Paulo: Global, 2001.

GRILO, DC Mapeamento de Bonfim de Feira. Relatório de Iniciação Cientifica. Feira de Santana: UEFS, 2008.

PITIA, AMA. Caracterização do meio fisico do distrito de Bonfim de Feira. Feira de Santana. In: SEMINARIO UEFS DE INICIACAO CIENTIFICA, 7, 2004, Feira de Santana. Anais ... Feira de Santana: PPPG/UEFS/CNPq/FAPESB, 2004.

ROSA, JG. Estas estórias. Rio de Janeiro: Nova Fronteira, 1985.

SILVA, AS. Caracterização do meio fisico do distrito de Bonfim de Feira. Feira de Santana. Relatório de Iniciação Cientifica. (orientação Gracinete Bastos de Souza), Feira de Santana: PPPG/UEFS, 2007.

SILVA, AS. Diagnóstico geoambiental do distrito Bonfim de Feira. Feira de Santana. Relatório de Iniciação Cientifica. (orientação Gracinete Bastos de Souza), Feira de Santana: PPPG/UEFS, 2008

\section{DOCUMENTOS CONSULTADOS:}

Acervo do Museu Casa do Sertão, UEFS

Acervo da Igreja do Senhor do Bonfim, Bonfim de Feira Jornal Folha do Norte, 1909, 1910, 1911

Jornal da Feira, 1932

Processos cíveis do Centro de Documentação da UEFS - CEDOC, 1906, 1940

Departamento de Imagem e Som da Fundação Cultural da Bahia - DIMAS

Documentos apresentados pela população contatada (recibo de energia elétrica, recbo da filarmônica, folhetos das festas católicas e afro-brasileiras) 